\title{
Energy efficiency as a key area of innovative economy of Russia
}

\author{
$P$ A Levchaev ${ }^{1, *}$ \\ ${ }^{1}$ Department of finances and credit, National Research Mordovia State University, Russia
}

\begin{abstract}
The article studies the cluster form of organization and financing for energy efficiency projects in the Republic of Mordovia «Energy efficient lighting engineering and intellectual lighting control system». Methodology of system approach allows revealing the purpose and objectives of the cluster, the structure and composition of its elemental base, the funding mechanism and the results. From the position of an integrated approach characterized by an innovative orientation of development of economy of region. Shown the most significant and promising projects in the field of energy efficiency - the production of modules for solar panels, energy-efficient housing construction and biogas plant.
\end{abstract}

\section{Introduction}

In the modern economy, energy efficiency issues are among the most important, as they determine the level of competitiveness of all participants in the relationship. Ceteris paribus, the more goods and services will produce the economic system, in the future more of its capabilities to the increment value. Therefore, the most important problems for economic entities are energy capacity-building and /or reduction of energy costs. It is desirable that the system maximizes the amount of goods and services produced by a constant amount of energy. More preferable is the economic growth of regional, national, global economies, accompanied by an increase in energy potential and, to an even greater extent, energy savings. The current economic structure is completely dependent on energy supply, and to produce and sell a product in a modern highly intelligent economy requires a leading position in energy production and efficient use. Energy as the main type of resources provides uninterrupted production processes in industry, agriculture, construction and other sectors of the national economy. The urgency of the problem is due to the fact that the energy intensity of the Russian economy is significantly higher than the world average (according to experts, about 3 times more than in advanced economic countries), which in turn negatively affects the competitiveness of domestic goods, as well as the structure of the entire economy, its prevailing and promising ways. Therefore, energy efficiency and energy saving are a significant reserve for the growth of the Russian economy. Methods: the study used a systematic, structural and functional scientific approaches, as well as methods of abstract and logical analysis and synthesis, economic generalizations. Keywords: energy efficiency, cluster, innovation, economy, region, development, systemic approach.

Energy efficiency and energy saving are topical at all levels of economic development. The purpose of such surveys is to provide necessary preconditions for the formation of the competitive characteristics of the Russian economy and its transition to a new qualitative level.

Modern economic structure is entirely dependent on the energy supply and to produce and to sell products in a modern high-tech economy requires a leading role for the production of energy and its efficient use. Energy, being one of the main types of resources, ensures continuity of production processes in industry, agriculture, construction and other sectors of the national economy. The dynamic development of these sectors often leads to the emergence of energy problems during periods of peak energy consumption. Therefore, one of the axioms of successful presence in the market is that economic system (micro, macro or mega wave), based on improved energy efficiency, ceteris paribus, more competitive in the present, but also potentially competitive in the future. One of the most important universal laws of development is that any system to strive to achieve results with minimal expenditure of energy. It is widely recognized that energy efficiency serves the least expensive and the fastest environmentally friendly way to meet energy needs, as according to experts the energy saving turns out to be 45 times more profitable than production of the same amount of energy.

In accordance with the energy efficiency strategy of Russia and the Federal target Programmer energy efficient economy, the policy framework of the Russian Federation in development of science and technologies priority directions of development: energy - saving technology; energy efficiency; electronics.

In 2009, Dmitry Medvedev in a Declaration to the Federal Assembly announced Russia's transition to an energy-saving development path. Attempts to improve the energy efficiency of production has been made previously, for example in 1996 was adopted the law "On energy saving". Questions of increase of energy

\footnotetext{
* Corresponding author: levchaevpa@yandex.ru
} 
efficiency were formulated in Energy strategy of Russia for the period till 2030 (the Order of the Government of the Russian Federation of November 13, 2009 N 1715p). In addition, the legislative support for the implemented measures is the Federal Law of November 23, 2009 № 261-FZ "On energy saving and energy efficiency and on amendments to certain legislative acts of the Russian Federation", regulating innovations in the state, municipal and private sectors. This law differs from the previous legal acts by its emphasis on the state and municipal sectors, as well as on the state of Affairs in the housing stock. Measures to improve energy efficiency should concern industry, housing, state and municipal institutions, public authorities and local selfgovernment, transport.

International competition and the struggle for the consumer forces producers to maintain a competitive level of products. The criterion of "price-quality" is largely determined by the ability to influence the cost of competitive and popular products. The network nature of the modern world economy, as well as the level of development of collective achievements inherent in the products, make it easy enough to satisfy almost all existing (as well as promising) requests of the average consumer for an affordable minimum price. However, in the race to meet the growing needs of human society is always relevant is the problem of energy efficiency. It concerns both the world leaders of production and wellknown brands, and producers determining the trends of local and regional markets.

It is considered that the world policy of energy saving and energy efficiency originates after the oil crisis of 1973 [1]. According to the well-known Kyoto Protocol, its signatories reduce harmful emissions of greenhouse gases or introduce trade in quotas for them. Priority in the practice of energy saving is the industry sector of transport (in terms of the impact of this sector on the level of greenhouse gas emissions), as well as the condition of the buildings (because according to experts, the share of buildings may have one fourth of the possible reduction in $\mathrm{CO} 2$ emissions in the period up to 2050).

In foreign practice, the most important direction of energy saving in recent years is to reduce energy consumption of lighting products - Australia; the EU countries are considering banning incandescent lamps. In the energy efficiency action Plan of 2006, the European Commission recognized that only low-cost savings account for about $20 \%$, and when it comes to technology, the potential is even greater. Thus, under the scenario of accelerated technology development, energy efficiency of buildings in industry and transport will reduce energy consumption by $17-33 \%$ by 2050 . In Denmark, according to the government's goals, by 2020 half of the total electricity will be generated at wind power plants, and by 2050 all energy demand should be provided from renewable energy sources (wind energy, biomass). A significant reduction in the use of fossil fuels is expected, for example, gas turbines of CHP plants should only support the supply of electricity in a short windless period. For the design of "smart" and integrated energy systems (involving integrated coordinated use of wind, solar, geothermal and other types of energy, biogas) the future.

The experience of the advanced projects will be extended further, to other regions that will result in improved energy efficiency throughout the economy.

According to the Russian news Agency "Federal Press" in many cities and regions of Russia implemented projects on energy efficiency (for example, "energy efficient quarter"), as well as to promote energy efficiency consumption [2]. In Moscow energy efficiency program is carried out for the period until 2020 - funding attracted more than 117 billion rubles. In St. Petersburg the financing of similar activities exceeded 100 billion rubles and pay special attention to economy in the public sector and to reduce energy consumption among the citizens. In Yekaterinburg operates Russian-German project "Yekaterinburg energy efficient city". In Nizhny Novgorod, a program of energy efficiency with funding of 38 billion rubles, Perm - 9,6 billion rubles, in Tyumen - 7.4 billion rubles.

According to the state program "energy Saving and energy efficiency up to 2020" it is planned to allocate 9.5 billion rubles, of which about $7 \%$ are allocated from the budgets of the Russian Federation and regions, and $73 \%$ from extra-budgetary sources. Among the main measures to stimulate and improve energy efficiency are the following: subsidies from the Federal budget for cofinancing programs and the provision of state guarantees to enterprises for loans for the implementation of relevant projects under long-term target agreements (it is assumed that state participation will not only be selective and aimed at the implementation of long-term activities, but preparing conditions for the launch of regional programs and stimulating conditions for business activation in this segment); maintenance of a system of target energy efficiency indicators in various sectors of the economy; support for R \& d on energy efficiency. Operational management of the programmer entrusted to the Federal state unitary enterprise "Russian energy Agency". In addition, the Russian energy Agency, the Ministry of energy of the Russian Federation and the world Bank have been implementing the "program Of targeted financing of energy efficiency projects in Russia" since 2012 in order to disseminate best practices in financing energy efficiency projects, as well as to promote energy saving solutions.

The basis of territorial and sectoral structure of regions is the economic efficiency of integration of industrial-economic relations of economic subjects for the most complete realization of joint economic potential. A modern form of optimization of production and economic interests of economic entities and other participants of economic relations is the cluster representing a relatively independent economic unit grouped of interrelated companies of the territory, characterized by specific properties. Such organization of joint activity of suppliers of products and services, institutions, infrastructure, helps to strengthen the competitive advantages of the project participants.

The complex nature of cluster organization allows the integration principles at all levels of management: 
1. consistency - the correlation of elements and components with the aim of achieving a synergy effect; 2. the interrelationship and sequence of implementation of management functions - coordination, planning, analysis, control, regulate;

3 according to the structural parts of the cluster to strategic directions of development.

At the regional level, regulatory legal acts aimed at regulating and supporting innovative industry and energy-saving technologies have been adopted. So in the Republic of Mordovia are: the Law of the Republic of Mordovia "On the Strategy of socio-economic development of the Republic of Mordovia until 2025", the government of the Republic of Mordovia "On approval of the Program to improve the investment attractiveness of the Republic of Mordovia for 2011 2015", the government of the Republic of Mordovia "On the Republican target program "energy Saving and energy efficiency in the Republic of Mordovia" for 2011 - 2020", the decree of the Government of the Republic of Mordovia "On providing financial support for scientific and technical activities and development of innovative projects in the Republic of Mordovia", the order of the Government of the Republic of Mordovia "On approval of the Concept of the Republican target program of scientific and innovative development of the Republic of Mordovia for 2010 - 2015".

In the Republic of Mordovia for the construction and development segments of the regional economy, meeting the highest modern requirements, implemented a number of programs.

1) the region has a program "energy Saving and increase of energy efficiency in the Republic of Mordovia for 2014-2016". The program is designed to encourage the overcoming of energy barriers to economic growth through the introduction of a complex of energy saving activities: 1) identifying potential energy savings; 2) ensure that the rate of reduction of energy consumption in economic sectors; 3) expanding the revenue side of the budget due to the reduction of irrational consumption of energy. Activities of this Program are balanced and cover all sectors of the economy, serve as a tool to enhance further development of the economy and technological upgrading in the region. Funding for the program is expected in the amount of 1 billion 843 million rubles from the budgets of different levels and extra-budgetary sources.

2) a national program to support the development of the innovation cluster "energy efficient lighting engineering and intellectual lighting control system". The cluster needs to become a leader in the domestic market. Competitive advantages: a) the leadership in the products they manufacture; b) the growing trend in the lighting industry; C) focus on implementation of a policy of the Government of the Russian Federation on stimulation of energy saving measures, qualitative change in lighting technology (the introduction of LEDs). The main objectives of the cluster: 1) the development of innovation infrastructure; promotion of innovation-based enterprises; 2) implementation of cooperation projects; 3 ) increasing the production and export of innovative products.
Currently the cluster consists of several components.

1) Managing company of the cluster - "TechnoparkMordovia". "Technopark-Mordovia" and data center (one of the largest in Europe), aims to commercialize scientific and industrial developments, the growing needs of the region and the country in the processing, transmission and storage of data in the information structure of the world economy. With the activities of Technopark linked to the dynamic development of energy-saving lighting engineering, electronics and instrumentation, as well as the formation of new industries - optoelectronics, believe that radio Photonics.

"Technopark-Mordovia" has the ability to subsidize costs in areas: 1) cooperation in scientific-technical sphere; 2) marketing, information and PR-support of participants; 3) the development of cluster cooperation with government authorities, development institutions, public organizations, other clusters; 4) organization and participation in exhibition and communication activities; 5) development of production capacity and production cooperation between Cluster participants.

Strategic management and monitoring of programmed activities managed by a focal point Ministry of industry, science and new technologies of the Republic of Mordovia.

2) of the national research Mordovian state University named after N. P. Ogarev. The University implements programs of research in the field of energy saving and new materials, has a unique specialized Lighting Department for training. In the context of research to develop new environmentally friendly and energy efficient sources of optical radiation, materials and components for a new generation of devices of radio engineering, optoelectronics and power electronics.

3) Scientific research Institute of light sources named after A. N. Lodygina. The Institute has developed more than $90 \%$ of light sources in the domestic market.

4) More than 10 large and medium-sized manufacturing companies. Their activities are aimed at introduction of energy saving technologies, development of promising sectors of the economy and increasing its energy efficiency: biogas, solar panels, creating "smart" housing.

5) Association of manufacturers of lighting products "Russian light", which brings together more than 40 lighting enterprises in Russia and abroad.

The structure of the cluster complex and diverse and involves the activation of economic relations with all levels of the budgetary system, economic actors. Financial security is implemented in the following forms: budget financing; self-financing; subsidies.

In 2013-2015 for the implementation of the programmer of support for the development of the innovation cluster "energy efficient lighting engineering and intellectual lighting control system" is planned to attract 7832,1783 thousand ruble. The Composition of sources of funds was varied: $13.5 \%$ of Federal budget; $64,3 \%$ - resources of the regional budget; $1,8 \%$ resources of the municipal budget; $20.4 \%$ of extrabudgetary sources of financing.

In the future the trend of increasing the share of the Federal budget, a slight decrease of the share of the 
regional budget, the reduction of income from extrabudgetary sources of funds and virtually complete absence of the municipal budget. This trend is due to the fact that the implemented program is characterized as regional in the context of strategic national development priorities of the country.

The members of the Cluster have been or are preparing to implement a complex of 26 investment projects in cooperation with domestic or foreign partners, estimated total cost 10342 million rubles, the growth Rate of performance indicators of the programmer (by 2012) are:

-the volume of work and projects in the field of research of $300 \%$;

-the volume of shipped innovative products (works and services) and growth of total revenue from sales of products in foreign markets to $250 \%$.

The efficient functioning of the financial mechanism of the cluster depends on the optimal functioning of its structure and orientation, compliance elements and components of the tasks scheduled. The functioning components of the cluster, the development of economic and technological processes requires a systematic approach of research and consideration of the synergy of interests of economic entities.

Interesting alternative energy project is the placement in the region of production modules for the solar industry with the creation of over 200 jobs. According to experts, solar energy is the fastest-growing segment of alternative energy. The annual rate of growth in the industry in recent times is over $50 \%$. The creation of the enterprise due to favorable investment and production opportunities in the region and the prospects of market power for Russian villages. The benefits of such power are the minimum risk of environmental disasters, the lack of wear mechanisms, mobility design and ease of maintenance. The participants of this agreement - the government of the Republic of Mordovia, the company "Helio-Resource", JSC "Electrovypryamitel".

Next project is designing and building energyefficient ("smart") homes. Energy-efficient - house, which reduced energy consumption without loss of quality accommodation. Here, the technology used renewable energy sources that reduce consumption of energy resources. The design of these houses is: heating the geothermal waters; use of solar collectors; the use of insulated walls and glass with a thermionic coating, energy-saving ventilation system, automatic lighting control, the system of energy accounting. In Mordovia the construction of energy efficient homes is part of the implementation of the regional program on resettlement of citizens from emergency housing. It is financed with Fund of assistance to reforming of Glisno utilities [3]. Ensuring the Program is carried out from budgets of all levels, extra-budgetary sources. The financial resources of the Program is 6614,5 million. Structure of funds: 0, 6 $\%$ - to Federal budget; $6.4 \%$ are funds from the Republican budget; $0,2 \%$ - funds from local budgets; $92.8 \%$ of the funds from extra budgetary sources.

Modern large-scale development project is the construction of Russia's largest biogas plant with a capacity of over $4 \mathrm{MW}$. This object appears near the capital of the Republic Saransk. In many developed countries there are special storage of solid waste of cities with the purpose of extraction of biogas for production of electric and thermal energy.

Bioenergy [4] is a promising sector of the economy. It allows you to solve the problems of obtaining fuel from biomass and the environment. Large-scale production of energy resources from plant materials nonfood uses, processing of agricultural waste and timber industry, woodworking plants, and organic and domestic waste can improve the environmental situation in the country. Biogas is a high quality carrier of energy and can be used in the household, average and small business, for the production of electricity, heating of residential and industrial premises. Economic and industrial effect bioenergetics is associated with the following factors:

-decrease of consumption of hydro carbonaceous fossil; -recycling of production wastes;

-reduction of harmful emissions and greenhouse gases into the environment;

-increasing the energy security of the region, country;

-highly effective fertilizer as an additional product of bioenergy production;

-decentralization of electricity supply.

This technology allows you to create waste-free environmentally friendly production. Raw material for the production of electricity being built in Mordovia biogas plant will be the waste products of cattle and beet pulp. In the enterprise will be interested in the agricultural region. A large part (about $4 \mathrm{MW}$ ) electricity will be supplied to network tariffs approved by Regional energy Commission, and the rest will be used for powering farms. Generated heat and byproduct biogas plant - organic fertilizer, will be used in greenhouse farms. This creates a sustainable closed cycle: plants food products (food) - waste plants. This system provides the region's agriculture fertilizer and feed, and production - energy and raw materials. This reduces the use of mineral energy sources and the release of gases that cause the greenhouse effect, pollution of the environment.

In Mordovia adopted the legal acts aimed at regulation and support of innovative economy and energy-saving technologies: the Law of the Republic of Mordovia "On the Strategy for socio-economic development of the Republic of Mordovia till 2025", the government of the Republic of Mordovia "On approval of the Program of increasing the investment attractiveness of the Republic of Mordovia for 2011 2015 years", decree of the Government of the Republic of Mordovia "On the Republican target program "energy Saving and increase of energy efficiency in Mordovia Republic" for 2011 - 2020", the decree of the Government of the Republic of Mordovia "On granting financial support to scientific and technical activity and development of innovative projects in the Republic of Mordovia", the Government decree of the Republic of Mordovia "On approving the Concept of the Republican target program of scientific and innovative development of the Republic of Mordovia for 2010 - 2015 years". The purpose of regulatory and legal support is the 
development of scientific and technical potential of the Russian Federation, implement measures aimed at reducing energy consumption while maintaining the corresponding useful effect from their use in the field of lighting engineering and intellectual lighting management systems $[8,9,10]$.

With a view to better realize the potential of the cluster of energy efficient projects in the region, subsequent to the effective decision of tasks it is advisable the use of adequate scientific tools. This is achievable through the implementation of scientific research approaches: the system, process, evolutionary, targeted. Modern approved method of comprehensive solution of financial and economic problems is the program-target method of planning. This method is in the target orientation of activity of economic subjects and planned resource provision - "goal - the way (objectives) - methods (activities) - resources". The priority is not the current organizational structure and management system elements, software, benchmarks, actions.

In the Republic of Mordovia successfully implementing a complex of programs on formation of the innovative environment and support for priority directions of science, technologies and techniques of Russia energy saving and efficiency. The peculiarity of the financial mechanism of the innovation cluster "energy efficient lighting engineering and intellectual lighting control system" is a flexible combination of budget financing, self-financing subsidies. An integrated scientific approach, the cluster method of program planning help you to achieve your objectives in accordance with resources development. This approach allows us to create high-tech background for development of the region for the formation of innovative structure of its economy [11-19].

By analogy with foreign practice in all regions of the country are gaining popularity design and creation of "smart" or energy-efficient homes. Energy efficient - a house that has significantly reduced (relatively average) energy consumption without losing the quality of living in it. In such projects, renewable energy technologies are used to significantly reduce energy consumption. The main design decisions of such houses are: heating at the expense of geothermal waters; use of a solar collector; the use of insulated walls and glass with thermion coating, as well as energy-saving recuperative ventilation system and automatic lighting control, equipment energy accounting system. In the Republic of Mordovia, the construction of such a house is carried out within the framework of the regional targeted program for the resettlement of citizens from dilapidated housing, and the financing of the program is carried out with the participation of the Fund to promote housing reform [6]. Provision of the Program is carried out at the expense of budgets of all levels, as well as extra-budgetary sources, and the amount of financial resources of the Program is 6614.5 million rubles. At the same time, 0, $6 \%$ comes from the Federal budget, $6.4 \%$ - from the Republican, 0.2 - from local budgets, and $92.8 \%$ is formed from extra-budgetary sources.
The mechanism of implementation of the energy efficiency Program of Mordovia is a set of measures of organizational, financial and economic nature, ensuring the effective implementation of energy-saving policies, as well as the interests of all parties. It includes the following main elements:

-energy saving through the implementation of energysaving programs and activities;

-stimulation of energy saving activities;

-financial and credit instruments providing for the rational use of budgetary funds;

-budget financing of energy-saving measures in the social sphere only in the presence of the developed project;

-ensuring control over the targeted use of funds;

-formation of infrastructure to support energy-saving activities.

Financing of energy-efficient technologies is considered as a key decision in the context of rising energy prices, since it is the high level of energy consumption of companies that is the incentive to invest in energy-efficient technologies. This need led to the development of various types of financial instruments offered by banks to companies. Such schemes make it possible to compensate companies for their investment in new equipment by saving energy costs. For example, by analogy with foreign experience, such financing schemes of energy efficiency programs as leasing, energy service contract and other specialized services are becoming more and more popular, as they stimulate enterprises to upgrade equipment without diverting a significant amount of scarce capital from the turnover.

If such a form of indirect long-term financing as leasing has long been known to the domestic economy, the energy service is a relatively new mechanism (although borrowed from the domestic economy from foreign practice) for solving energy efficiency problems. Under the energy service contract refers to the contract for the introduction of energy-saving technologies, involving the implementation of a specialized energy service company a full range of works on the introduction of energy-saving technologies in the customer enterprise with the involvement of credit resources. Thus, the energy service contract involves a combination of various contracts, namely: contract, services, financial lease, orders, etc. it is Significant that the payment of funds is made after the implementation of the project and at the expense of savings from energysaving technologies (from 6 months to 5 years).

The key financial benefits for the customer's company are cost savings (no need to divert them from the turnover), payment for planned activities at the expense of future savings, reducing the cost of repairs of inefficient equipment, professional management of the project and subsequent engineering support.

Among the options developed to reduce the energy intensity of the economies of developed countries, there are various forms of direct and indirect impact, such as the use of tax incentives for enterprises that implement measures to improve energy efficiency of production, the promotion of energy savings by end users and the control of energy consumption in public tasks, as well as 
the intensification of developments in the field of renewable energy sources.

Thus, in unison with international practice, Russia is in full swing taking measures to transition the economy to energy-saving technologies. This applies to both the public sector and all sectors of the economy, end users of services. Introduction of energy consumption metering devices, logistic schemes of optimization of energy saving processes of territories and production, various financial and credit methods of activation of implementation of energy efficient projects, construction of "smart" houses, transfer of urban transport to power supply - this is an incomplete list of currently implemented programs. However, the country still faces ambitious targets to improve efficiency, from energy production and distribution to energy consumption. This is the requirement of the time, because in the modern world competition standards of profit maximization are largely based on prudent and energy-efficient production.

\section{Results}

The study allowed us to draw the following conclusions:

Among the developed options for reducing the energy intensity of the economy of developed countries, there are various forms of direct and indirect impact: the use of tax incentives for enterprises implementing measures to improve the energy efficiency of production, stimulating energy saving by end users and controlling energy consumption in public tasks, as well as the intensification of developments in the field of renewable energy sources.

Now in Russia, effectively apply the following energy efficiency programs: the introduction of metering of energy consumption, logistics schemes optimization of energy saving processes of territories and industries, and various financial-credit methods of enhancing the implementation of energy efficiency projects, building "smart" homes, the translation of public transport on the power supply.

As practice shows at various stages of implemented innovative energy-efficient projects, the following sources of financial support should be used:

-own funds of economic entities (profit, depreciation); -commercial debt financing in the form of short -, medium - and long-term loans. It is planned to use the resources of commercial banks, as well as compensation of interest on loans received for the implementation of investment projects in the field of energy efficiency. It is also possible to lease equipment, the mechanism of public-private partnership.

-budget financing for efficient energy-saving projects with great social effect. It is carried out at the expense of: a) subsidies to the subjects of the Russian Federation for the implementation of energy efficiency programs; b) subsidies to regional and local budgets within the framework of targeted programs for the implementation of energy saving measures; C) targeted funding for the implementation of Regional energy saving programs and energy efficiency from the regional and local budgets; d) tax credits.

-means of competitive actions for implementation of projects of the target orientation. It is possible to receive grants within the framework of Russian and international energy efficiency programs, as well as joint financing of projects by foreign funds and international organizations.

In particular, in the Republic of Mordovia successfully implemented a set of programs aimed at creating a unique innovative environment that implements program activities to support such priority areas of science, technology and technology of Russia as energy saving and energy efficiency. Features of the financial mechanism of the innovative territorial cluster of Mordovia "energy-efficient lighting and intelligent lighting control systems" are characterized by a flexible combination of forms of budget financing and selffinancing, subsidies.

Despite the positive trends in the field of energy saving, the implementation of the existing potential is hampered by constraints of different nature: price and financial, related to the structure and organization of the economy and market; institutional; social, behavioral. All of these can be addressed through targeted energy efficiency policies. We are talking about the development and consistent implementation of a longterm strategy in this area, coordination of efforts of the Executive and legislative authorities, joint work of Federal and Republican authorities, local selfgovernment, large, medium and small businesses, as well as the formation and debugging of mechanisms of interaction of all participants in the process.

\section{Conclusion}

Thus, in unison with international practice, Russia is in full swing taking measures to transition the economy to energy-saving technologies. This applies to the public sector and all sectors of the economy, end users of services.

An integrated approach to solving energy efficiency problems at all levels, allows us to hope for an effective solution to the most ambitious projects and maintain the current rate of economic growth. It is necessary to use all possible Arsenal of financial and credit levers and instruments and economic incentives and preferences. Otherwise, there will be no large-scale cumulative synergetic effect of the implemented activities and projects.

The country faces ambitious targets to improve efficiency, from energy production and distribution to energy consumption. This is the requirement of the time, because in the modern world competition standards of profit maximization are largely based on prudent and energy-efficient production.

\section{References}

[1] Energy efficiency, Energy policy development, challenges and opportunities, energy Charter Secretariat, with the participation of the European 
Bank for reconstruction and development and Euroheat \& Power (2007).

[2] Energy efficiency of russian towns FederalPress [Electronic resource]. Available at: http://old.fedpress.ru/federal/polit/analit/id_26732 7.html.

[3] Federalnii portal Protown [Electronic resource]. Available at: http://www.protown.ru/russia/obl/articles/article 325.html.

[4] P.A. Levchaev, The Economics of a New Technological Order (Financial Aspects of the Innovation Vector of Economic Development of the Region, Germany: Palmarium Academic Publishing, 15-100, 2015).

[5] P.A. Levchaev, The concept of innovation value in economy of the global financial crisis, International journal of applied and fundamental, research, Moscow, 3, 14-15 (2015) [Electronic resource]. Available at: http://www.sciencesd.com/pdf/2015/3/24949.pdf.

[6] M.A. Klishina, Survey of regions programs saving energies, Budget [Electronic resource]. Available at: http: // bujet.ru/article/119915.php.

[7] P.A. Levchaev, Perspective innovation and modernization of model development, Russian economy Finance and credit, Moscow, 23, 2-7 (2011).

[8] Official state site of Republic Mordovia [Electronic resource]. Available at: http://www.emordovia.ru/content/view/378.

[9] The program development National research Mordovian State University in 2010-2019 [Electronic resource]. Available at: http://www.mrsu.ru/ru/niu/index.php?IBLOCK I $\mathrm{D}=2077$.

[10] Park of hi-tech "Mordovia" [Electronic resource]. Available at: http://www.technoparkmordovia.ru/.

[11] V.V. Markin, Formation of Region System of Strategic Management of Energy Efficiency, Sanct-Peterburg: Sanct-Peterburg of State engineering-economy university (2008).

[12] Energy efficiency houses at the Northwest of Russia, Mechanism of financing project by energy efficiency houses [Electronic resource]. Available at: $\underline{\text { http://undp- }}$ eeb.ru/index.php?option $=$ com content $\& v i e w=a r t i$ cle\&id=30\%3A2012-01-20-20-04$45 \&$ catid $=4 \&$ Itemid $=37$ \&lang $=$ ru.

[13] E.G. Gasho, A.V. Koval, M.I. Postelnick, Integrated approach and logistics of the territorial energy management: the unity of technical, organizational, economic and information solutions Sat. reports of the open seminar "Economic problems of the energy complex", M.: Institute of economic forecasting, RAS (2004).

[14] Glushenkov, Lighting and control system exterior lighting Energy Efficiency, 4, 22-23, 2013).

[15] Energy saving is the most important condition for innovative development of agriculture: materials of the International scientific and technical conference, Minsk: bgatu, 421 (2013).

[16] A. Harutyunyan, A Fundamentals of Energy Conservation: monograph, (M: Energy, 15, (2014).

[17] V.A. Komkov, Energy Saving in Housing and Communal Services (M: INFRA-M, 320, 2013).

[18] Assessment of economic efficiency of energy saving (Theory and practice, Moscow: Heat Power, 400 (2015).

[19] O.V. Sviderskaya, Fundamentals of Energy Saving (Moscow: Tetrasystems, 176, 2016). 